\title{
Expression of aquaporin-1 is a poor prognostic factor for stage II and III colon cancer
}

\author{
TORU YOSHIDA, SHOZO HOJO, SHINICHI SEKINE, SHIGEAKI SAWADA, TOMOYUKI OKUMURA, \\ TAKUYA NAGATA, YUTAKA SHIMADA and KAZUHIRO TSUKADA
}

Department of Surgery and Science, Graduate School of Medicine and Pharmaceutical Sciences, University of Toyama, Toyama, Toyama 930-0194, Japan

Received March 3, 2013; Accepted July 17, 2013

DOI: $10.3892 / \mathrm{mco} .2013 .165$

\begin{abstract}
Colorectal cancer is a major cause of cancer-related mortality worldwide, with a high incidence of recurrence following curative resection, particularly among patients with stage II and III disease. There is therefore a need for novel prognostic biomarkers for advanced colon cancer and it was recently reported that aquaporin-1 (AQP1) may be associated with aggressive characteristics of colon cancer cells in experimental data. The association of clinicopathological findings with AQP1 expression was evaluated by tissue microarray (TMA) analysis, to determine whether AQP1 is a prognostic biomarker for colon cancer. A total of 120 consecutive stage II and III colon cancer patients (51 with stage II and 69 with stage III) who underwent curative resection between 1997 and 2008 were analyzed. The TMA was prepared from archival formalin-fixed, paraffin-embedded tissue blocks. Immunostaining was graded semi-quantitatively by considering the staining intensity and the percentage of positive tumor cells. Results showed the AQP1-positive rate to be $35.8 \%$. The expression of AQP1 was associated with lymph node metastasis, lymphovascular and vascular invasion. The 5-year survival rate of the AQP1-positive and -negative groups was 73.7 and $87.9 \%$, respectively. The survival rate of the positive group was significantly lower compared to that of the negative group $(\mathrm{P}=0.030)$. Furthermore, the expression of AQP1 was an independent poor prognostic factor according to the multivariate analysis. Therefore, AQP1 may be a promising candidate as a prognostic biomarker for colon cancer.
\end{abstract}

\section{Introduction}

Colorectal cancer is a major cause of cancer-related mortality worldwide, causing 500,000 deaths annually (1). Following curative resection, there is a considerable risk of recurrence

Correspondence to: Dr Toru Yoshida, Department of Surgery and Science, Graduate School of Medicine and Pharmaceutical Sciences, University of Toyama, 2630 Sugitani, Toyama, Toyama 930-0194, Japan E-mail: yoshidat@med.u-toyama.ac.jp

Key words: aquaporin-1, colon cancer, tissue microarray in patients with stage II and III disease. Recurrence occurs in $\sim 20 \%$ of stage II patients and $\sim 50 \%$ of the stage III patients may be cured with surgery alone (2-5). Therefore, it is critical to identify patients with a high risk of recurrence.

Aquaporins (AQPs) are a family of small membrane transport proteins that assemble in cell membranes as tetramers and primarily act as water-selective pores that facilitate the osmotically-driven transport of water across plasma membranes $(6,7)$.

AQP1 is expressed in vascular endothelial cells throughout the body is not expressed in the central nervous, genital, lymphoid and gastrointestinal systems, including the colonic mucosa $(8,9)$. It was reported that several types of cancer express AQP1 and it may be involved in carcinogenesis $(10,11)$. An in vitro study demonstrated that AQP1-mediated plasma membrane water permeability is crucial for colon cancer cell migration and may be associated with tumor invasion and metastasis (12). However, available data on the clinical significance of AQP1 in colon cancer are limited. In the present study, the association of AQP1 expression in colon cancer with clinicopathological findings was evaluated using tissue microarray (TMA) analysis and it was demonstrated that AQP1 is a prognostic factor for advanced colon cancer.

\section{Materials and methods}

Patients. A total of 168 consecutive stage II and III colon cancer patients who underwent curative resection between January, 1997 and August, 2008 were investigated. The final stage was pathologically confirmed according to the International Union Against Cancer (UICC) classification system, 7th edition. The degree of lymphovascular and vascular invasion was classified as negative, mild or severe by the pathologists of our hospital. Patients with rectosigmoid cancer were included in this study. Tissue microarrays were prepared from each tumor and a representative area was carefully selected from a hematoxylin and eosin (H\&E)-stained section. A total of 120 patients (51 cases with stage II and 69 cases with stage III disease) with no other causes of death were subjected to statistical analysis.

Tissue microarray. A TMA is composed of small 1.0-mmcores of tissue obtained from paraffin blocks. For tissue stamping, the tumor areas were marked on H\&E-stained sections and 
A

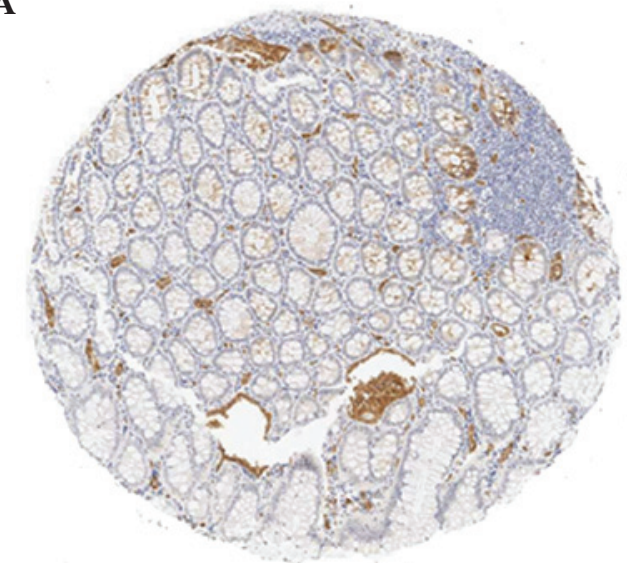

C

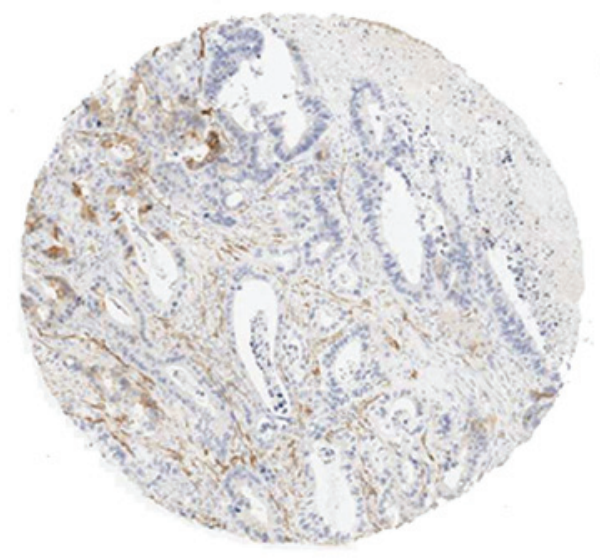

B

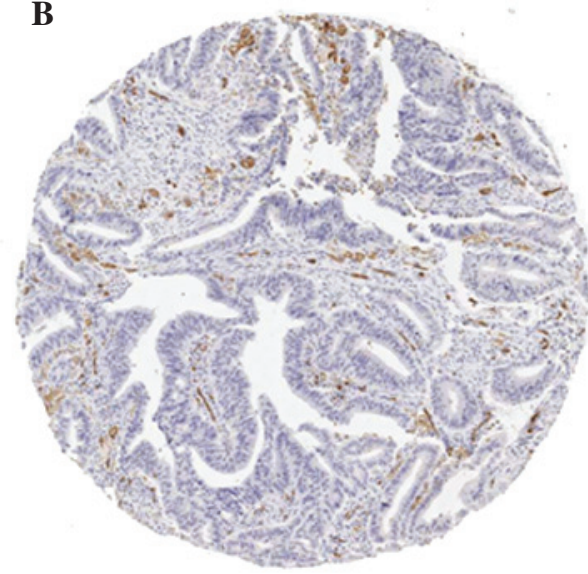

D

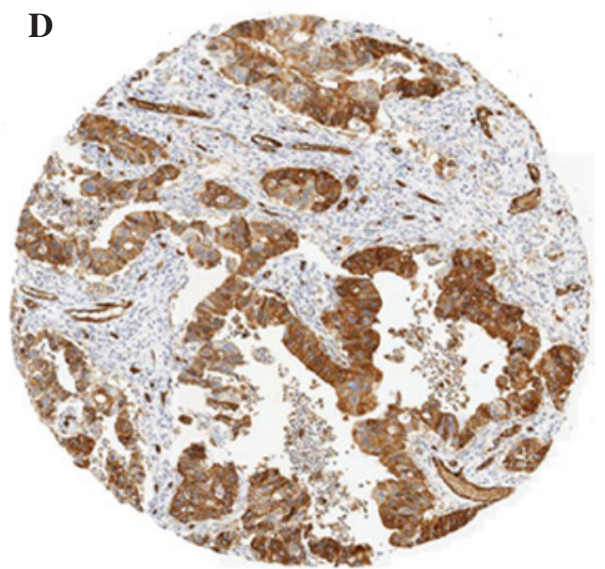

Figure 1. Immunostaining for aquaporin-1 (AQP1) on tissue microarray (TMA). (A) The normal mucosal epithelium exhibited no AQP1 staining, (B) score 0, (C) score 2 (intensity 1, distribution 1) and (D) score 4 (intensity 2, distribution 2). The AQP1 score was (A) 0 in 64 patients (53.3\%), (B) 2 in 13 patients (10.8\%), (C) 3 in 17 patients (14.2\%) and (D) 4 in 26 patients (21.7\%).

then marked directly on the corresponding formalin-fixed, paraffin-embedded tissue blocks. Paraffin-embedded tumor material was cut into $4-\mu \mathrm{m}$ sections and placed onto glass slides, followed by staining with H\&E and anti-AQP1 antibody (H-55; Santa Cruz Biotechnology, Inc., Santa Cruz, CA, USA) at a 1:100 dilution. Immunostaining of the TMAs was graded semi-quantitatively by considering the staining intensity and the percentage of positive tumor cells by two pathologists who were blinded to the clinicopathological variables. The staining intensity was scored using three grades as follows: 0 , no staining of cancer cells; 1 , weak staining; and 2, strong staining. The percentage of stained tumor cells was classified on a scale of 3 grades: 0 , no positive cells; $1,<50 \%$ positive cancer cells; and $2,>50 \%$ positive cancer cells (Fig. 1). The AQP1 expression by the tumor was defined as positive when the sum of the intensity and the extent scores was $\geq 3$ and as negative when the score was $<3$.

Statistical analysis. The JMP-9 software package was used for statistical analysis. AQP1 expression was analyzed as nominal data. The association between AQP1 expression and clinicopathological characteristics was analyzed using the $\chi^{2}$ test or the two-sided Student's t-test, as appropriate. Survival was assessed by the Kaplan-Meier method and compared by the log-rank test. The multivariate analysis was performed using
Cox's proportional hazards model to evaluate risk factors for cancer-related mortality. $\mathrm{P}<0.05$ was considered to indicate a statistically significant difference.

\section{Results}

Patient characteristics. The clinical characteristics of the 120 colon cancer patients are summarized in Table I. Ninety-two percent of the patients had tumor invasion deeper than pT3 and 8 cases had pT4b. Lymph node metastasis was identified in $57.5 \%$ of the patients. Lymphovascular and vascular invasion were positive in 68.4 and $60.0 \%$ of the patients, respectively. Postoperative chemotherapy was administered to $57.5 \%$ of the patients and the regimens were as follows: UFT in 43 patients, LV/UFT in 9, CDDP/5FU in 3 , FOLFOX in 3 and FOLFIRI in 9 patients. The recurrence rate of this series was $25.8 \%$.

Immunohistochemical staining for $A Q P 1$. To evaluate the expression of AQP1 in colon cancer, immunostaining of 120 paraffin-embedded primary colon cancer specimens was performed. The normal epithelium exhibited no AQP1 staining (Fig. 1A). The AQP1 score was 0 in 64 (53.3\%), 2 in 13 (10.8\%), 3 in $17(14.2 \%)$ and 4 in 26 patients $(21.7 \%)$. The incidence of AQP1-positive expression in colon cancer (score $\geq 3$ ) was $35.9 \%$ (43/120) (Table I). 
Table I. Patient clinicopathological characterisitics.

\begin{tabular}{lll}
\hline Characteristics & No. & $\%$ \\
\hline
\end{tabular}

Age (years)
$<75$
$\geq 75$

Gender

Male

Female

Tumor location

Right

Left

Depth of invasion ${ }^{\mathrm{a}}$

pT1
pT2
pT3
pT4a
pT4b

Bowel obstruction

Yes

No

Lymph node involvement ${ }^{\mathrm{a}}$

$\begin{array}{ll}\mathrm{pN} 0 & 51 \\ \mathrm{pN} 1 & 51 \\ \mathrm{pN} 2 & 18\end{array}$

Differentiation

High

Moderate

Poor/Muc/Sig

Lymphovascular invasion

Negative

Mild

Severe

Vascular invasion

Negative

Mild

Severe

CEA

$<3.5$

$\geq 3.5$

CA19-9

$<37$

$\geq 37$

Postoperative chemotherapy

$$
\text { Yes }
$$

No

Recurrence

Yes

No
Table I. Continued.

\begin{tabular}{lll}
\hline Characteristics & No. & $\%$ \\
\hline AQP1 score $^{\mathrm{b}}$ & & \\
0 & 64 & 53.3 \\
2 & 13 & 10.8 \\
3 & 17 & 14.2 \\
4 & 26 & 21.7 \\
\hline
\end{tabular}

${ }^{a}$ UICC classification system, 7 th edition. ${ }^{\text {b}}$ The AQP1 score is the sum of the intensity score (0-2) and the extent score (0-2) and was 0 in 64 patients $(53.3 \%), 2$ in 13 patients $(10.8 \%), 3$ in 17 patients $(14.2 \%)$ and 4 in 26 patients $(21.7 \%)$. The incidence of AQP1-positive expression in colon cancer (score $\geq 3$ ) was $35.9 \%$ (43/120). Right, ascending and transverse colon; Left, descending and sigmoid colon; Muc, mucinous carcinoma; Sig, signet ring cell carcinoma; CEA, carcinoembryonic antigen; CA, carbohydrate antigen.

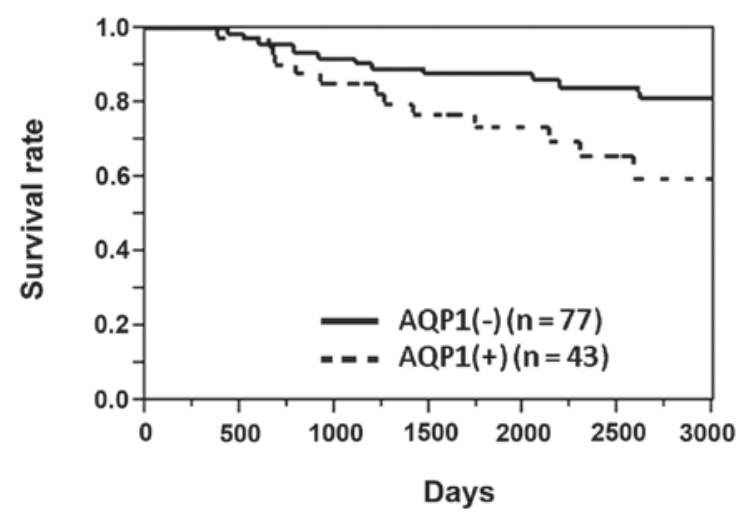

Figure 2. Overall survival rate of colon cancer patients with and without aquaporin-1 (AQP1) expression. The 5-year survival rate of AQP1-positive and -negative patients was 73.5 and $87.9 \%$, respectively. The survival rate of AQP1-positive patients was significantly lower compared to that of $\mathrm{AQP1}$-negative patients $(\mathrm{P}=0.030$, log-rank test).

Survival. The 5-year survival rate of the 120 patients was $83.1 \%$. The 5-year survival rates of AQP1-positive and -negative patients were 73.5 and $87.9 \%$, respectively. The survival rate of AQP1-positive patients was significantly lower compared to that of AQP1-negative patients $(\mathrm{P}=0.030$, log-rank test $)$ (Fig. 2).
57.5

38.3

73.3

18.3
Correlation of $A Q P 1$ expression with clinicopathological factors. The association of AQP1 expression with clinicopathological factors is shown in Table II. The AQP1 expression exhibited a significant correlation with lymph node metastasis $(\mathrm{P}=0.042)$, severe lymphovascular invasion $(\mathrm{P}=0.012)$ and vascular invasion $(\mathrm{P}=0.017)$. AQP1 expression was also higher in left-sided compared to that in right-sided colon cancer $(\mathrm{P}=0.038)$. Only one of the 10 poorly differentiated adenocarcinomas expressed AQP1, although the difference was not statistically significant.

Prognostic impact of $A Q P 1$ expression. The association of various clinical factors to the prognosis is shown in Table III. 
Table II. Association between patient characteristics and AQP1 expression in colon cancer.

\begin{tabular}{|c|c|c|c|c|c|c|c|}
\hline \multirow[b]{2}{*}{ Characteristics } & \multicolumn{2}{|c|}{$\mathrm{AQP}{ }^{\mathrm{a}}$ overexpression } & \multirow[b]{2}{*}{ P-value } & Factors & \multirow[t]{2}{*}{ No. } & \multirow[t]{2}{*}{$5 y-O S$} & \multirow[t]{2}{*}{ P-value } \\
\hline & $(-)$ & $(+)$ & & Age (years) & & & \\
\hline Age (years) & & & & $\begin{array}{l}<75 \\
>75\end{array}$ & $\begin{array}{l}92 \\
28\end{array}$ & $\begin{array}{l}87.4 \\
697\end{array}$ & $0.0001^{\mathrm{a}}$ \\
\hline$<75$ & 60 & 32 & 0.663 & Gender & & & \\
\hline$\geq 75$ & 17 & 11 & & Male & 65 & 87.9 & 0.061 \\
\hline Gender & & & & Female & 55 & 77.5 & \\
\hline Male & 40 & 25 & 0.513 & Tumor location & & & \\
\hline Female & 37 & 18 & & Right & 55 & 75.7 & $0.019^{\mathrm{a}}$ \\
\hline Tumor location & & & & Left & 63 & 89.8 & \\
\hline Right & 42 & 15 & 0.038 & Depth of invasion & & & \\
\hline Left & 35 & 28 & & pT $1,2,3,4 \mathrm{a}$ & 112 & 84.7 & $0.0004^{\mathrm{a}}$ \\
\hline Depth of invasion & & & & pT4b & 8 & 62.5 & \\
\hline pT1 & 1 & 0 & 0.779 & Bowel obstruction & & & \\
\hline pT2 & $\begin{array}{r}5 \\
5\end{array}$ & $\begin{array}{r}3 \\
27\end{array}$ & & Yes & 14 & 64.2 & $0.029^{\mathrm{a}}$ \\
\hline pT3 & 54 & 27 & & No & 106 & 86.0 & \\
\hline pT4a & $\begin{array}{r}11 \\
6\end{array}$ & 11 & & Differentiation & & & \\
\hline p140 & 0 & 2 & & High & 58 & 78.8 & 0.167 \\
\hline $\begin{array}{l}\text { Bowel obstruction } \\
\text { Yes }\end{array}$ & 8 & 6 & 0.774 & Other & 62 & 87.6 & \\
\hline $\begin{array}{l}\text { Yes } \\
\text { No }\end{array}$ & $\begin{array}{r}0 \\
69\end{array}$ & 37 & & Lymphovascular invasion & & & \\
\hline Lymph node involvement & & & & Negative-mild & 92 & 86.2 & 0.245 \\
\hline $\begin{array}{l}\text { Lymph node invorvement } \\
\text { pNO }\end{array}$ & 38 & 13 & 0.042 & Severe & 28 & 73.1 & \\
\hline $\mathrm{pN} 1, \mathrm{~N} 2$ & 39 & 30 & & $\begin{array}{l}\text { Vascular invasion } \\
\text { Negative-mild }\end{array}$ & 79 & 82.9 & 0.626 \\
\hline $\begin{array}{l}\text { Differentiation } \\
\text { High, moderate }\end{array}$ & 68 & 42 & 0.151 & $\begin{array}{l}\text { Severe } \\
\text { Lymph node involvement }\end{array}$ & 41 & 83.4 & \\
\hline Poor/Muc/Sig & 9 & 1 & & Negative & 51 & 92.0 & $0.049^{\mathrm{a}}$ \\
\hline Lymphovascular invasion & & & & Positive & 69 & 76.1 & \\
\hline Negative-mild & 64 & 27 & 0.012 & CEA & & & \\
\hline Severe & 13 & 16 & & $<3.5$ & 69 & 93.8 & $0.004^{\mathrm{a}}$ \\
\hline Vascular invasion & & & & $\geq 3.5$ & 46 & 72.3 & \\
\hline Negative-mild & 59 & 24 & 0.017 & CA19-9 & & & \\
\hline Severe & 18 & 19 & & $<37$ & 89 & 91.4 & 0.086 \\
\hline CEA & & & & $\geq 37$ & 22 & 68.1 & \\
\hline$<3.5$ & 42 & 27 & 0.476 & Postoperative chemotherapy & & & \\
\hline$\geq 3.5$ & 31 & 15 & & Yes & 69 & 85.9 & 0.085 \\
\hline CA19-9 & & & & No & 51 & 79.4 & \\
\hline$<37$ & 55 & 33 & 0.517 & AQP1 & & & \\
\hline$\geq 37$ & 16 & 6 & & Negative & 77 & 87.9 & $0.030^{\mathrm{a}}$ \\
\hline $\begin{array}{l}\text { Postoperative chemotherapy } \\
\text { Yes }\end{array}$ & 39 & 30 & 0.057 & Positive & 43 & 73.7 & \\
\hline
\end{tabular}

Table III. Kaplan-Meier analysis of factors related to overall survival.

${ }^{a}$ The differences in survival rates were compared using the log-rank test. Statistical significance was determined as $\mathrm{P}<0.05$. The factors associated with poor prognosis were age $\geq 75$ years $(\mathrm{P}=0.0001)$, right colon cancer $(\mathrm{P}=0.019)$, pT4b $(\mathrm{P}=0.0004)$, lymph node metastasis $(\mathrm{P}=0.049)$, bowel obstruction by the tumor $(\mathrm{P}=0.028), \mathrm{CEA} \geq 3.5(\mathrm{P}=0.004)$ and aquaporin-1 (AQP1) positivity $(\mathrm{P}=0.030)$. 5y-OS, 5-year overall survival; Right, ascending and transverse colon; Left, descending and sigmoid

aAquaporin-1 (AQP1) expression was defined as positive when the sum of the intensity and the extent scores was $3 / 4$ and as negative when the score was $0-2$. The AQP1 expression exhibited a significant correlation with lymph node metastasis $(\mathrm{P}=0.042)$, severe lymphovascular invasion $(\mathrm{P}=0.012)$ and vascular invasion $(\mathrm{P}=0.017)$. The AQP1 expression was also higher in left-sided compared to right-sided colon cancer $(\mathrm{P}=0.038)$. Only $1 / 10$ of poorly differentiated adenocarcinomas expressed AQP1, although the difference was not statistically significant. Right, ascending and transverse colon; Left, descending and sigmoid colon; Muc, mucinous carcinoma; Sig, signet ring cell carcinoma; CEA, carcinoembryonic antigen; CA, carbohydrate antigen.

\begin{abstract}
colon; CEA, carcinoembryonic antigen; CA, carbohydrate antigen.
\end{abstract}
The factors associated with poor prognosis were age $\geq 75$ years $(\mathrm{P}=0.0001)$, right colon cancer $(\mathrm{P}=0.019), \mathrm{pT} 4 \mathrm{~b}(\mathrm{P}=0.0004)$, lymph node metastasis $(\mathrm{P}=0.049)$, bowel obstruction by the tumor $(\mathrm{P}=0.029), \mathrm{CEA} \geq 3.5(\mathrm{P}=0.004)$ and AQP1 positivity 
Table IV. Multivariate analysis of factors associated with overall survival.

\begin{tabular}{|c|c|c|c|c|}
\hline \multirow[b]{2}{*}{ Factors } & \multirow[b]{2}{*}{ Risk ratio } & \multicolumn{2}{|c|}{$95 \% \mathrm{CI}$} & \multirow[b]{2}{*}{ P-value } \\
\hline & & Lower & Upper & \\
\hline Age $\geq 75$ years & 3.209 & 1.202 & 8.789 & $0.020^{\mathrm{a}}$ \\
\hline Right colon cancer & 1.642 & 0.606 & 4.821 & 0.334 \\
\hline Bowel obstruction & 1.130 & 0.328 & 3.361 & 0.829 \\
\hline pT4b & 7.968 & 2.098 & 24.995 & $0.004^{\mathrm{a}}$ \\
\hline Lymph node involvement & 2.299 & 0.840 & 7.102 & 0.107 \\
\hline $\mathrm{CEA} \geq 3.5$ & 3.254 & 1.193 & 9.754 & $0.021^{\mathrm{a}}$ \\
\hline AQP1+ & 2.593 & 1.057 & 6.439 & $0.038^{\mathrm{a}}$ \\
\hline
\end{tabular}

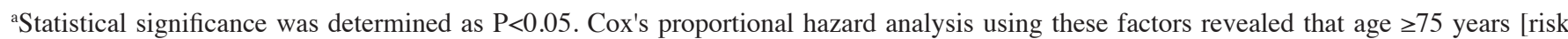
ratio $(R R)=3.20 ; P=0.020]$, $p T 4(R R=7.96 ; P=0.004)$, a high CEA level $(R R=3.25 ; P=0.021)$ and $A Q P 1$ positivity $(R R=2.59 ; P=0.038)$ were independent poor prognostic factors. CI, confidence interval; CEA, carcinoembryonic antigen; AQP1, aquaporin-1.

$(\mathrm{P}=0.030)$. Furthermore, the Cox's proportional hazard analysis using these factors revealed that age $\geq 75$ years [risk ratio $(\mathrm{RR})=3.209 ; \mathrm{P}=0.020]$, $\mathrm{pT} 4 \mathrm{~b}(\mathrm{RR}=7.968 ; \mathrm{P}=0.004)$, a high CEA level $(\mathrm{RR}=3.254 ; \mathrm{P}=0.021)$ and $\mathrm{AQP} 1$ positivity $(\mathrm{RR}=2.593 ; \mathrm{P}=0.038)$ were independent poor prognostic factors (Table IV).

\section{Discussion}

The AQPs are a family of small ( 30-kDa monomers) membrane transport proteins that assemble in cell membranes as tetramers and primarily act as water-selective pores, facilitating the osmotically-driven transport of water across plasma membranes $(6,7)$. Recently, various studies have focused on the association of AQPs and cancer (10-17).

AQP1 is expressed in vascular endothelial cells throughout the body, except in the normal central nervous, genital and lymphoid systems. This molecule is also not expressed by normal colonic epithelial glands (6-9). It was reported that several types of cancer express AQP1 and it may be involved in tumor invasion and metastasis. Hu et al (13) demonstrated that AQP1 expression by tumor cells may increase local invasiveness and the ability to metastasize by comparing B16F10 melanoma and 4T1 breast tumor mouse cell lines with or without AQP1 expression. The results of that study demonstrated that AQP1 expression increased the water permeability of the plasma membrane and the migration of cancer cells in vitro.

In addition, Moon et al (10) reported that AQP1 was associated with colorectal carcinogenesis and Yiang (12) reported that the AQP1 activity in plasma membranes affected HT20 colon cancer cell migration in vitro. Those findings revealed that the expression of AQP1 is associated with tumor progression in colon cancer. Our findings also suggested that AQP1 is associated with cancer progression.

Furthermore, our study demonstrated that AQP1 expression is a predictor of advanced colon cancer. The overexpression of AQP1 has already been demonstrated to be a prognostic indicator in basal cell carcinoma of the breast (14), clear cell renal cell carcinoma (15) and lung carcinoma (16). However, there have been no previous studies on the association of
AQP1 with the prognosis of colon cancer. To the best of our knowledge, this was the first study to demonstrate that AQP1 is a prognostic biomarker for colon cancer.

Of note, although AQP1 overexpression is a poor prognostic factor for breast, lung and colon cancer, it is a good prognostic factor for renal carcinoma. The reason for this difference has not been elucidated thus far. Furthermore, our study, we observed that the AQP1 expression in poorly differentiated adenocarcinoma was low, although low differentiation is considered to be included among the poor prognostic factors and AQP1 expression was predicted to be high in this histological type. However, only two of the 10 cases of poorly differentiated carcinoma exhibited recurrence in our series. More cases of poorly differentiated adenocarcinoma should be investigated to elucidate these inconsistencies.

Although postoperative chemotherapy was shown to affect treatment outcomes, the effect was not statistically significant, which may be attributed to the use of ineffective regimens. The effects of postoperative chemotherapy were assessed according to AQP1 expression and there was no observed difference (data not shown). This result may not immediately prove the validity of postoperative chemotherapy. Recently designed standard regimens, such as FOLFOX, may improve the prognosis of high-risk colon cancer patients.

The possibility of targeting AQP1 for the treatment of colon cancer was recently suggested. Bin et al (17) reported that acetazolamide, a carbonic anhydrase inhibitor $\left(\right.$ Diamox $\left.^{\circledR}\right)$ that is used to treat glaucoma and epilepsy, inhibited AQP1 expression and colon cancer xenograft tumor growth. Therefore, AQP1 may be a prognostic factor as well as a treatment target in colon cancer.

In conclusion, the expression of AQP1 is associated with characteristics of progression of colon cancer, such as lymph node metastasis and lymphovascular invasion and is a poor prognostic factor for advanced colon cancer. These clinical results are consistent with previous experimental findings that support the association of AQP1 with factors such as tumor growth, invasiveness and metastasis. Therefore, AQP1 is a molecule that requires further investigation regarding the prognostic evaluation and treatment of colon cancer. 


\section{Acknowledgements}

This study was supported by grants from the Ministry of Education, Culture, Sports, Science and Technology of Japan.

\section{References}

1. Parkin DM, Bray F, Ferlay J and Pisani P: Global cancer statistics, 2002. CA Cancer J Clin 55: 74-108, 2005.

2. Gill S, Loprinzi CL, Sargent DJ, Thomé SD, Alberts SR, Haller DG, Benedetti J, Francini G, Shepherd LE, Francois Seitz J, Labianca R, Chen W, Cha SS, Heldebrant MP and Goldberg RM: Pooled analysis of fluorouracil-based adjuvant therapy for stage II and III colon cancer: who benefits and by how much? J Clin Oncol 22: 1797-1806, 2004.

3. André T, Quinaux E, Louvet C, Colin P, Gamelin E, Bouche O, Achille E, Piedbois P, Tubiana-Mathieu N, Boutan-Laroze A Flesch M, Lledo G, Raoul Y, Debrix I, Buyse M and de Gramont A: Phase III study comparing a semimonthly with a monthly regimen of fluorouracil and leucovorin as adjuvant treatment for stage II and III colon cancer patients: final results of GERCOR C96.1. J Clin Oncol 25: 3732-3738, 2007.

4. Mamounas E, Wieand S, Wolmark N, Wolmark N, Bear HD, Atkins JN, Song K, Jones J and Rockette H: Comparative efficacy of adjuvant chemotherapy in patients with Dukes' B versus Dukes' C colon cancer: results from four National Surgical Adjuvant Breast and Bowel Project adjuvant studies (C-01, C-02, C-03, and C-04). J Clin Oncol 17: 1349-1355, 1999.

5. Le Voyer TE, Sigurdson ER, Hanlon AL, Hanlon AL, Mayer RJ, Macdonald JS, Catalano PJ and Haller DG: Colon cancer survival is associated with increasing number of lymph nodes analyzed: a secondary survey of intergroup trial INT-0089. J Clin Oncol 21: 2912-2919, 2003

6. Agre P, King LS, Yasui M, Guggino WB, Ottersen OP, Fujiyoshi Y, Engel A and Nielsen S: Aquaporin water channels - from atomic structure to clinical medicine. J Physiol 542: 3-16, 2002.
7. Verkman AS and Mitra AK: Structure and function of aquaporin water channels. Am J Physiol Renal Physiol 278: F13-F28, 2000.

8. Mobasheri A and Marples D: Expression of the AQP-1 water channel in normal human tissues: a semiquantitative study using tissue microarray technology. Am J Physiol Cell Physiol 286: C529-C537, 2004.

9. Bondy C, Chin E, Smith BL, Preston GM and Agre P: Developmental gene expression and tissue distribution of the CHIP28 water-channel protein. Proc Natl Acad Sci USA 90: 4500-4504, 1993.

10. Moon C, Soria JC, Jang SJ, Lee J, Obaidul Hoque M, Sibony M, Trink B, Chang YS, Sidransky D and Mao L: Involvement of aquaporins in colorectal carcinogenesis. Oncogene 22: 6699-6703, 2003.

11. Yang JH, Shi YF, Chen XD and Qi WJ: The influence of aquaporin-1 and microvessel density on ovarian carcinogenesis and ascites formation. Int J Gynecol Cancer 16: 400-405, 2006.

12. Yiang J: Aquaporin-1 activity of plasma membrane affects HT20 colon cancer cell migration. IUBMB Life 61: 1001-1009, 2009.

13. Hu J and Verkman AS: Increased migration and metastatic potential of tumor cells expressing aquaporin water channels. FASEB J 20: 1892-1894, 2006.

14. Otterbach F, Callies R, Adamzik M, Kimmig R, Siffert W, Schmid KW and Bankfalvi A: Aquaporin (AQP1) expression is a novel characteristic feature of a particularly aggresive subgroup of basal-like breast carcinomas. Breast Cancer Res Treat 120: 67-76, 2010.

15. Huang Y, Murakami T, Sano F, Kondo K, Nakaigawa N, Kishida T, Kubota Y, Nagashima Y and Yao M: Expression of aquaporin 1 in primary renal tumors: a prognostic indicator for clear-cell renal cell carcinoma. Eur Urol 56: 690-698, 2009.

16. Machida Y, Ueda Y, Shimasaki M, Sato K, Sagawa M, Katsuda S and Sakuma T: Relationship of aquaporin 1, 3, and 5 expression in lung cancer cells to cellular differentiation, invasive growth, and metastasis potential. Hum Pathol 42: 669-678, 2011.

17. Bin K and Shi-Peng Z: Acetazolamide inhibits aquaporin-1 expression and colon cancer xenograft tumor growth. Hepatogastroenterology 58: 110-111, 2011. 